\title{
Metro, ritmo y puntuación en los repertorios hispánicos de refranes (siglos XVI-XVII)
}

\section{Meter, rhythm, and punctuation in the Hispanic collections of proverbs (16th-17th centuries)}

\section{ELENA Llamas-Pombo}

Instituto de Estudios Medievales, Renacentistas y de

Humanidades Digitales

Universidad de Salamanca

Plaza de Anaya, s/n. Salamanca, 37008

pombo@usal.es

Orcid ID 0000-0002-8791-3958

Resumen: Como contribución a la historia de la puntuación española y a la perspectiva grafemática en el estudio de la fraseología histórica, se analiza la puntuación de los refranes en la edición impresa de cinco repertorios de los siglos XVI y XVII. Partiendo de las bases de la métrica española y de una teoría lingüística de la puntuación, nuestros objetivos son: valorar si los signos de puntuación corresponden o no a pausas de la oralidad y comprobar cuál ha sido la evolución del tratamiento gráfico dado a la conjunción e/y. Se argumentará a favor de la existencia de usos puntuarios autónomos, no ligados a la prosodia, que desmienten el mito de la supuesta oralidad y valor respiratorio y prosódico de la puntuación preacadémica. Fuentes: Proverbios (1500) y Refranes que dizen las viejas (1522) del Marqués de Santillana, Refranes glosados (1524) y Refranes de Núñez de Toledo (1555 y 1621).

Palabras clave: Refranes. Puntuación. Ritmo. Oralidad. Conjunción e/y.
RECIBIDO: 2 DE NOVIEMBRE DE 2017 ACEPTADO: 7 DE DICIEMBRE DE 2017
Abstract: As a contribution to the history of Spanish punctuation and to the graphematic perspective in the study of historical phraseology, we analyze the punctuation of sayings in the printed edition of five repertoires of the 16th and 17th centuries. Starting from the bases of Spanish metrics and a linguistic theory of punctuation, our objectives are: to assess whether punctuation marks correspond or not to pauses of orality and to verify the evolution of the graphic treatment given to the conjunction $e / y$. We will argue in favor of the existence of autonomous punctuation marks, not linked to prosody, that refute the myth of the supposed "orality" or respiratory and prosodic value of punctuation before academic standardization. Sources: Proverbios (1500) and Refranes que dizen las viejas (1522) of the Marqués de Santillana, Refranes glosados (1524) and Refranes of Núñez de Toledo (1555 y 1621).

Keywords: Proverbs. Punctuation. Rhythm. Orality. Conjunction e/y.

\footnotetext{
* Este trabajo se ha realizado en el marco del Proyecto de investigación de I+D+i FFI2017-84404-P Enunciación y marcas de oralidad en la diacronía del francés, del Ministerio de Economía y Competitividad de España. En este artículo, nos proponemos aplicar al refranero español fundamentos teóricos de la lingüística francesa, en los campos de la lingiuística de la puntuación y de la paremiología.
} 
INTRODUCCIÓN: FRASEOLOGÍA HISTÓRICA Y ORTOGRAFÍA

E 1 estudio de la Fraseología histórica de la lengua española, entendida como el establecimiento de la diacronía global de las unidades fraseológicas, es una disciplina lingüística que conoce actualmente un desarrollo notable dentro de la Historia de la lengua española, tal como han puesto de manifiesto recientemente Echenique Elizondo, Martínez Alcalde y Sánchez Méndez en un trabajo programático sobre esta línea de investigación, que conjuga la diacronía fraseológica con la bistoria de la codificación gramatical y con la lexicografía bistórica aplicada al español (19). Atañen a esta investigación, esencialmente, los procesos diacrónicos de lexicalización gramaticalizada (diacronía), la valoración de la fraseología como ejemplo de uso de la lengua (codificación) y los problemas de su inserción lexicográfica (bistoriografía).

La perspectiva ortográfica puede igualmente hallar su lugar entre los objetivos de esta disciplina, pero se trata de un aspecto al que aún no se le ha prestado una atención suficiente, como subrayan los mencionados lingüistas (17 y 28), al identificar la necesidad de estudiar "los procesos de fijación gramatical en la representación gráfica de las unidades fraseológicas". Interesan, por ejemplo, las alternancias gráficas que han presentado a lo largo del tiempo las unidades, "en cuanto a la unión y separación de elementos de determinadas locuciones".

En este artículo, como contribución a dicha perspectiva ortográfica o grafemática y a la historia de la puntuación española, proponemos el estudio de la puntuación en las unidades paremiológicas.

Desde un punto de vista grafemático, los signos de puntuación conforman las unidades gráficas suprasegmentales de la lengua escrita y pueden o bien constituir una notación abstracta de elementos fónicos tales como las pausas o la entonación, o bien funcionar de modo autónomo, sin correspondencia con dichos elementos suprasegmentales orales. En esta doble propiedad radica el interés de situar los estudios de la puntuación en el plano diamésico de variantes de la lengua, esto es, en una historia de las relaciones entre los códigos fónico y gráfico. En un trabajo anterior, analizamos la puntuación antigua y contemporánea del Romancero hispánico, a partir de las propiedades del verso oral, así como las implicaciones de los diferentes criterios de edición y puntuación (Trapero/Llamas-Pombo).

Dos rasgos esenciales de los refranes los inscriben en el ámbito de la oralidad: su carácter rítmico y su frecuente adscripción intuitiva por parte de los locutores a la tradición oral de la lengua. Los proverbios, sin embargo, son 
unidades fraseológicas incorporadas a las obras escritas en lenguas romances desde la literatura medieval y los repertorios renacentistas. Interesa, pues, a la historia de la puntuación, la evolución del tratamiento gráfico dado a la notación del ritmo, como propiedad de las paremias en el habla. El estudio de los refranes desde el ámbito particular de la puntuación converge así en esa fundamental y continua historia hispánica de trasvase mutuo entre la tradición oral y la literatura, entre la oralidad y la escritura.

Con el fin de orientar metodológicamente tal estudio de las relaciones entre las tradiciones ortotipográficas de los siglos XVI y XVII y la estructura rítmica de los proverbios, hemos de partir de una serie de postulados teóricos y terminológicos previos. ${ }^{1}$

\section{TERMINOLOGÍA Y METODOLOGÍA PARA LA HISTORIA \\ DE LA PUNTUACIÓN ESPAÑOLA}

\section{Ortografía como competencia lingüística}

La descripción de la puntuación empleada en estadios pasados de la lengua escrita puede responder a varios objetivos. El primero de ellos es el ecdótico: la comprensión de los antiguos usos puntuarios permite enseñar a leer rectamente los textos y a editarlos conforme a su tenor. Desde esta perspectiva, puede realizarse una verdadera crítica textual sobre los signos de puntuación y su mayor o menor fidelidad a la autoría de las obras. Ejemplares en esta perspectiva son los trabajos de Sebastián Mediavilla, por ejemplo, sobre la puntuación de los textos de Cervantes (2017).

Una segunda finalidad, de orden lingüístico, es la de clasificar los usos prototípicos de cada época y la elaboración de una tipología de formas y funciones; tipología que atañe a la historia de la ortografía y que, como todo fenómeno en evolución, ha de contar con un marco teórico que contemple los parámetros de la variación.

Ahora bien, con el fin de establecer tal tipología de usos antiguos, hemos de partir del análisis concreto de las prácticas manuscritas o impresas de cada

1. Se mencionarán, en este artículo, los estudios estrictamente imprescindibles para nuestra argumentación, evitando realizar aquí un "estado de la cuestión" sobre historia de la puntuación española; el lector podrá encontrar dicho "estado de la cuestión" en la bibliografía de los estudios más generales (Santiago 1996; 1998; Sebastián Mediavilla 2001; 2002; 2017; Luque Moreno; Carrera Díaz; Llamas-Pombo 2008). 
autor, copista, escribano o tipógrafo. En trabajos anteriores, hemos propuesto un estudio de la puntuación que no escape a la finalidad última de la lingüística, entendida, en el sentido coseriano, como explicitación de la competencia y el saber intuitivo de los locutores. Una lingüística de la puntuación destinada a reconstruir el saber intuitivo del antiguo usuario de la escritura y su competencia lingüística en el sistema gráfico (Coseriu 70; Llamas-Pombo 2007, 13-15; 2009, 231).

En el proceso de formalización y definición de aquellas unidades gráficas, el historiador de la lengua constata a menudo el carácter irregular, variable o asistemático de los usos puntuarios en periodos de incipiente estandarización gráfica. Es esencial, en este estudio, evitar el llamado -en palabras de Zumthor (24)- "prejuicio teleológico", consistente en "reducir el antes de la norma a una anticipación del después", al considerar "imperfectas" o "incorrectas" las puntuaciones no estandarizadas del pasado. Es el peligro sobre el que, precisamente, se ha reflexionado de modo sagaz en un número anterior de Rilce: "el error de aplicar anacrónicamente nuestro conocimiento de la lengua actual a la aprensión de la lengua antigua" (López Serena 695). La sola percepción de una alteridad entre nuestros usos y los antiguos no basta para desentrañar los principios de escritura vigentes para el "escriptor" que trabajaba en un contexto de laxitud normativa, comúnmente más permisiva con la variación de lo que lo es la norma moderna. Concretamente, es importante evitar dos anacronismos: la aplicación de nuestro sistema actual, muy jerarquizado en tres grados, a los textos de los siglos XVI y XVII, y el engañoso calco de la función de los signos antiguos sobre su función actual.

\section{Puntuación como marca inmanente de la escritura}

Partimos de una premisa que atañe a la relación entre las dos sustancias de la lengua: la escritura no es un mero registro o calco gráfico de la palabra oral, sino que constituye en sí misma "un análisis lingüístico en diversos grados de consciencia”, según la fórmula empleada por Hagège (102). La puntuación y los signos no alfabéticos hacen explícitas las unidades gráficas que distinguían -o no distinguían- los usuarios de la escritura; nos permiten comprobar cómo estructuraban las articulaciones del discurso y el encadenamiento de sus elementos.

Es necesario prescindir de una idea preconcebida que se repite aún en los mejores estudios de los que disponemos para la puntuación contemporánea y 
que podemos denominar, con Boucheron-Pétillon (24), el mito de la oralidad; esto es, una simplificación de la historia de la puntuación como mutación progresiva desde la notación prosódica hasta la notación autónoma de unidades lógicas y gramaticales. Según este leitmotiv, los signos medievales de la puntuación de las lenguas romances habrían tenido una función esencialmente rítmica o respiratoria, y la puntuación de los impresos habría permanecido, en los comienzos de la imprenta, subordinada a la lectura en voz alta (Figueras 2001, 18; Dahlet 11).

Este mito de la oralidad puede ser rebatido, sin embargo, por la propia evolución de las ideas sobre la puntuación. Por ejemplo, en la historiografía de la lengua inglesa, Bruthiaux (35) ha identificado tanto gramáticos que explican en el siglo XVI la dimensión estructural de la puntuación, como autores tardíos que siguen invocando su dimensión prosódica. En la historiografía lingüística del francés, Boucheron-Pétillon (24) y Anis (1983, 31-33; 2004, 5-6) han examinado, en la historia de la gramática y la lexicografía francesas, esta tensión irresuelta entre la función respiratoria de la puntuación y sus funciones de articulación sintáctico-semántica. En trabajos anteriores, hemos intentado demostrar que los textos medievales romances presentan ya usos autónomos de la puntuación, junto a pautas de la oralidad (por ejemplo, Llamas-Pombo 2009 y 2016), en la misma proporción en que pueden presentarlos los textos contemporáneos. Sabemos que un tercio de los signos de puntuación actuales no tiene correspondencia prosódica (Védénina 144; Nunberg 12). Pongamos el ejemplo prototípico que nos ofrece Rosenblat, en un estudio pionero sobre los valores inmanentes de la grafía: el uso de la coma en la norma actual no corresponde necesariamente a una pausa. "En las respuestas corrientes: «Sí, señor», «No, señor». «iSí, hombre!», etc., no se hace nunca pausa donde se marca la coma" (60). En la lengua hablada, tampoco se acentúa ni se realiza una pausa tras la conjunción $y$ que sí aparece puntuada en la lengua escrita en enunciados como: "El mendicante se detuvo, y, apoyado a dos manos en el bordón, contempló la aldea [...]” (Rosenblat 59). ${ }^{2}$ En este artículo, se valorará

2. Los desajustes entre lo prosódico y lo ortográfico quedaron planteados exhaustivamente desde 1974, en los trabajos pioneros de José Polo sobre ortografía y ciencia del lenguaje (por ejemplo 302-05). De este autor nos permitimos tomar el término puntuario, para aludir a 'lo relativo o perteneciente a la puntuación'. Los principios básicos de una ortografía como ciencia de la escritura inmanente, no dependiente de la oralidad, fueron establecidos con gran fundamento teórico por Lidia Contreras (123-57). Los valores inmanentes de la puntuación actual y su necesario análisis independiente de la lengua hablada han sido ampliamente argumentados por Figueras $(2001 ; 2014)$ y Sánchez Iglesias. 
la puntuación del refranero en el plano diamésico, para establecer qué usos de la puntuación responden a unidades prosódicas y qué usos son grafías autónomas, inmanentes, marcas "para el ojo", sin correspondencia con elementos fónicos.

\section{El proverbio español como estrofa}

La existencia de un patrón métrico como propiedad formal de los proverbios siempre ha estado presente en las definiciones tradicionales de este tipo de fraseología, propiedad que ha sido analizada con criterios lingüísticos por Anscombre (2000; 2004; 2012), seguido por otros autores como Darbord (173-76) o Martin. El patrón métrico surge como manifestación de una propiedad más general aún de los proverbios en todas las lenguas: su carácter rítmico (Anscombre 2012; Marcon; D’Andrea). Dicho en los términos de la métrica española: el proverbio reúne las propiedades que constituyen una estrofa; según la definición de Quilis (87), posee un axis rítmico o participación de hasta cuatro elementos del sonido (acento, cantidad, tono y rima). Por ejemplo: el pareado, que forma por sí solo una estrofa, interviene en la formación de refranes, con versos que pueden ser iguales (Al que a buen árbol se arrima, buena sombra le cobija, $\mathrm{a}_{8}+\mathrm{a}_{8}$, con rima asonante $i-a$ ) o bien diferentes. Un ejemplo de forma estrófica mayor: el proverbio Cuando las barbas de tu vecino veas pelar, echa las tuyas a remojar es asimilado por Anscombre $(2004,80)$ a la estrofa de un quinteto, con isometría de cinco sílabas y un esquema abaca: los versos impares tienen rima asonante y uniforme, y los pares fluctúan libremente. Una métrica afín a la del romancillo:

$\begin{array}{ll}\text { Cuando las barbas } & \mathrm{a}_{5} \\ \text { de tu vecino } & \mathrm{b}_{5} \\ \text { veas pelar, } & \mathrm{a}_{5}(4+1) \\ \text { echa las tuyas } & \mathrm{c}_{5} \\ \text { a remojar } & \mathrm{a}_{5(4+1)}\end{array}$

Deteniéndonos en el concepto de axis rítmico, observamos que Quilis lo define como "conjunción de cuatro elementos sonoros", es decir, como propiedades verbales que únicamente se realizan en la oralidad. Se trata de la concepción del ritmo basada en el movimiento que establecieron los formalistas rusos Brik y Tomachevski, para distinguirlo del metro, distinción que consi- 
deramos aplicable a la naturaleza de los refranes: solo el metro puede ser fijado por la escritura, porque el ritmo es movimiento únicamente existente en la oralidad:

Es necesario distinguir rigurosamente el movimiento del resultado del movimiento. Si una persona salta sobre un terreno pantanoso y deja sus huellas, aunque la sucesión de esas huellas sea regular, no constituye un ritmo. Los saltos se realizan según un ritmo, pero las huellas que estos dejan sobre el suelo no son más que datos que nos sirven para juzgarlos [...]. Del mismo modo, el poema impreso en un libro no ofrece más que las huellas del movimiento. Solo el discurso poético puede ser presentado como un ritmo y no su resultado gráfico [...]. No se puede comprender el ritmo a partir de la línea de los versos; por el contrario, se comprenderá el verso a partir del movimiento rítmico. (Brik y Tomachevski, en Todorov 143-69; la traducción es nuestra)

La paremiología francesa cuenta con estudios recientes que han indagado en un concepto de ritmo que aúna tanto las características métricas como las diferentes formas de repetición fonética, léxica y morfosintáctica. D’Andrea (104-07), siguiendo a Benveniste, ha restituido el sentido etimológico del griego rbythmós; 'disposición', 'forma distintiva', en ruptura con la tradición occidental que le ha atribuido durante siglos el sentido de 'movimiento regular'. D’Andrea interpreta así todo tipo de paralelismo o repetición de los proverbios como una realización del "principio de equivalencia" en la función poética del lenguaje: "La función poética proyecta el principio de la equivalencia del eje de la selección sobre el eje de la combinación" (Jakobson 138). La citada lingüista distingue seis parámetros rítmicos a los que sería interesante someter los refranes españoles: más allá del ritmo estrófico, su modelo permite explicar iteraciones con valor rítmico, aunque no métrico. Por ejemplo (107): el proverbio francés Qui dort, dîne (esquema bimembre de 2+1 sílabas, cuyo valor rítmico se halla en la equivalencia fonética, anáfora de sonidos o aliteración $[\mathrm{d}] /[\mathrm{d}])$.

En trabajos recientes de corte semántico, como el de García-Borrón (3236), aunque no se tiene en cuenta la teoría paremiológica francesa (Anscombre, D'Andrea, etc.), no se deja de aludir, bajo el término de "juegos de palabras", a las paronimias y otras figuras de iteración fónica, como recurso verbal propio de numerosos refranes en español (del tipo: Quien dijo "pobre", dijo "podre"; Vecina, bocina, etc.). 


\section{Hechos de lengua, hechos de habla y puntuación}

Consideremos, a continuación, los elementos lingüísticos que nos pueden permitir valorar si la puntuación escrita corresponde a la oralidad de los refranes; si es posible comparar objetivamente la función de un signo escrito con la sonora dicción oral de un enunciado. Ciertamente, el lingüista no puede imaginar o reconstruir como locutor actual los elementos prosódicos de estadios antiguos de la lengua; ahora bien, el cómputo métrico de los versos sí constituye un parámetro fijo y objetivo de la prosodia de un enunciado; sobre una unidad métrica, sí podemos evaluar la equivalencia suprasegmental o la autonomía funcional de los signos de puntuación, dado que las unidades métricas implican hechos de habla, esto es, nos informan sobre la oralidad.

Siguiendo a Quilis (39), podemos recordar que, al medir la cantidad de un verso, el número de sus sílabas fonológicas es un becho de lengua, mientras que fenómenos como la sinalefa son bechos de babla, que adquieren, circunstancialmente, un valor métrico. De hecho, la sinalefa es un fenómeno corriente y prácticamente constante en el habla (44). Examinemos, a continuación, la puntuación de algunos versos del célebre manual de Quilis, partiendo de su definición de sinalefa: "cuando una palabra termina en vocal (o vocales) y la siguiente comienza por vocal (o vocales), se computan, junto con las consonantes que formen sílaba con ellas, como una sola sílaba métrica" (41).

a) Los signos de pausa (la coma, por ejemplo), corresponden a menudo a una pausa $\mathrm{o}$, al menos, a una juntura o frontera suprasegmental:

desjarretar un toro, /o estrangular un león (Rubén Darío, en Quilis 65)

Podemos leer las sílabas [“des-ja-rre-tar-un-to-ro” (7) "oes-tran-gu-lar-unleón” (6+1=7)], con sinalefa en oes-trangular y sinéresis en león, más una sílaba. "La sinalefa toro o que se produciría en un verso simple, aquí no se realiza por mor de la cesura" (Quilis 65). Por consiguiente, la coma de la escritura sí constituye la marca de una frontera prosódica.

b) Pero, en otros casos, las comas de los autores y editores no corresponden a pausa alguna, cuando se hallan entre sílabas unidas en el babla por una sinalefa:

¡Hola, hidalgos y escuderos

de mi alcurnia y mi blasón! (Duque de Rivas, en Quilis 23) 
Para que el primer verso sea octosílabo, el poeta cuenta con la sinalefa "labidalgos", además de "yescuderos" y "mialcurnia". La coma que articula el saludo Hola no puede corresponder a pausa alguna; responde a una norma escrita que impone separar las interjecciones de los vocativos, pero no tiene la función de representar obligatoriamente una pausa oral. Ocurre lo mismo en la siguiente estrofa de endecasílabos:

De la pasada edad, ¿qué me ha quedado?

$\mathrm{O}$ ¿qué tengo yo, a dicha, en lo que espero

sin ninguna noticia de mi hado (Epístola moral a Fabio, en Quilis 43)

Los versos cumplen el imperativo de las once sílabas, gracias a la sinalefa " yoadicha" y al biato "de mi\#hado". Hay coma para leer el complemento a dicha separado del resto de la frase; sin embargo, en el habla, no hay pausa alguna entre yo y a dicha.

c) Lo afirmado en (b) no queda invalidado por un tercer caso de sinalefa: aquella que se produce a pesar de una pausa no obligada en el interior de un verso. En efecto, a diferencia de la pausa estrófica y de la pausa versal, la pausa interna sí permite la sinalefa. Ejemplo: hay articulación prosódica interna entre "llanto" y "a lástima" aunque dentro de una sinalefa o secuencia vocálica única en los versos:

Dejad que a voces /diga el bien que pierdo, // si con mi llanto / a lástima os provoco; // (Francisco de Quevedo, en Quilis 71)

\section{PUNTUACIÓN Y MARCAS GRÁFICAS DE DELIMITACIÓN DE PROVERBIOS EN LIBROS IMPRESOS}

Este análisis requiere, obviamente, el acceso a las fuentes impresas originales y a una revisión individual de los usos de cada impresor, imposible de realizar mediante consulta de concordancias, dado que no disponemos de corpus digitales con puntuación original. En los ejemplos citados a continuación, transcribiremos fielmente la puntuación, el uso del espacio en blanco y la secuenciación gráfica, así como el tratamiento grafémico o abreviado de las conjunciones $e / y$. Solamente se desarrollarán, por motivos de legibilidad, las abreviaturas de consonantes nasales, indicándolo en letra cursiva. 
Ausencia de signos de secuenciación sintáctica

En los comienzos de la imprenta, la poesía renacentista era habitualmente editada con una puntuación mínima o con total ausencia de puntuación. Por ejemplo, el Cancionero de Juan del Enzina de 1496 o los romances en pliegos sueltos del siglo XVI aparecen totalmente desprovistos de puntuación (Trapero/Llamas-Pombo). Las colecciones de refranes ordenados alfabéticamente responden en ocasiones a este tratamiento "no interpretativo", "no gramaticalizado" de los proverbios que se afirma recoger de la tradición oral. Es el tipo de transcripción que presentan los Refranes que dizen las viejas detras del fuego del Marqués de Santillana, en su edición de 1522. A excepción del punto final de cada línea, no hay signo gráfico que distinga la frecuente estructura bimembre del proverbio o el funcionamiento de la conjunción y como conector pragmático. Presentan el mismo tratamiento los elementos coordinados por $y$ con valor de 'suma y adición',

Callate y callemos que sendas nos tenemos.

Dezir y hazer no es para todos los hombres.

así como aquellos valores de $y$ con valor de conector argumentativo que permite interpretar otros valores inferidos del contexto discursivo:

valor concesivo ( $y=$ ' $y$ sin embargo');

Aun no ensillays 7 ya cavalgays.

valor adversativo $(y=$ 'pero');

Açoten me en concejo y no lo digan en mi casa.

Aldeana es la gallina y come la el de sevilla.

Come con el y guarte del.

valor consecutivo ( $y=$ ' $y$ por consiguiente');

Ayamos paz y moriremos viejos.

Cabra y magra y trefe y mal pesada

Nótese que la distinción entre los dos valores de la conjunción y se materializa en el uso de la coma en la puntuación moderna. Por ejemplo, este último refrán es editado por Martínez de Carnero de este modo: Cabra y magra y trefe, y mal pesada ('Cuando la dádiva es poca y miserable, entonces merece ser escarnecida'). 
Solo, excepcionalmente, un refrán aparece puntuado en todo el impreso, con un uso característico del comma, como marca del carácter bimembre de numerosas paremias, que encontramos sistemáticamente en otros impresos.

Yo a vos por honrrar:vos a mi por encornudar

(fol. 12v)

Obsérvese (siguiendo la teoría de Anscombre 2004) que el bimembrismo semántico no conlleva obligatoriamente la existencia de un pareado. En este caso, la estructura rítmica del refrán parece responder a un esquema métrico de tipo $4+4+4+6$, basado en la siguiente configuración rítmica: si transcribimos por el signo $\cup$ una sílaba no acentuada y por el signo - una sílaba acentuada (siguiendo a Anscombre 2000),

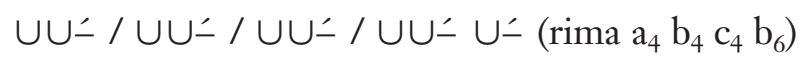

\section{Puntuación mínima y tratamiento de la conjunción e/y (s. XVI)}

Una de las tradiciones de puntuación del latín medieval que pasa a las lenguas romances es el uso de un signo de puntuación delante de la conjunción et/ely (Llamas-Pombo 2018). Su alto grado de generalización y pervivencia a lo largo de los siglos, desde los más antiguos textos documentales, queda patente en aquellos impresos en los que se trata del único elemento verbal dotado de puntuación. El modelo estrófico de refranes nos puede proporcionar ejemplos característicos. Examinaremos, concretamente, la versión editada en Salamanca en 1500 de los Proverbios de gloriosa doctrina del Marqués de Santillana.

Las coplas de pie quebrado o estrofa de octosílabos que alternan con versos de cuatro sílabas estuvieron muy difundidas en el siglo XV y principios del XVI por los poetas de los cancioneros, como el Marqués de Santillana, quien en estos Proverbios emplea el esquema $\mathrm{a}_{8} \mathrm{~b}_{4} \mathrm{~b}_{8} \mathrm{a}_{4} \mathrm{a}_{8} \mathrm{c}_{4} \mathrm{c}_{8} \mathrm{a}_{4}$. Por ejemplo:

$\begin{array}{llll}\text { A los libres pertenece } & \mathrm{a}_{8} & \\ \text { Aprender } & \mathrm{b}_{4} & \\ \text { Donde se muestra el saber } & \mathrm{b}_{8} & \\ \text { E florece } & \mathrm{a}_{4} & \\ \text { Ciertamente bien meresce } & \mathrm{a}_{8} & \\ \text { Preminencia } & \mathrm{c}_{4} & \\ \text { quien de doctrina: } 7 \text { prudencia } & \mathrm{c}_{8} & \\ \text { Se guarnece } & \mathrm{a}_{4} & \text { (fol. 11r) }\end{array}$


Esta edición presenta cada estrofa glosada con una correspondencia entre cada verso y cada línea, resaltada visualmente por una mayúscula inicial de verso (marca gráfica de la unidad de versificación que ha permanecido en la poesía francesa desde los primeros poemas medievales hasta la poesía moderna, pero que no se ha perpetuado en las tradiciones gráficas hispánicas). Como se ha señalado anteriormente, este tipo de disposición gráfica versal contenía una puntuación mínima en la poesía renacentista, cuando no una total ausencia de puntuación.

La única puntuación interna del verso, en este impreso, es la que recae delante de la conjunción $e$ (habitualmente abreviada) con la figura $<:>$ como "signo de puntuación débil", que denominaremos comma, mediante el término medieval más extendido; el que sigue empleando, por ejemplo, Nebrija (es de gran utilidad el cuadro de Sebastián Mediavilla 2002, 37, autor que recoge toda la compleja diversidad terminológica de la puntuación en el siglo XVI). No emplearemos la denominación "dos puntos", pues nos parece desafortunada, precisamente, por el posible anacronismo de atribuir a los usos antiguos valores del signo actual que recibe el mismo nombre.

La conjunción aparece tratada de un modo irregular, entendiendo por "irregular" aquel uso de un signo que no tiene valor de regla en todos los casos de análoga estructura sintáctica o semántica. Antes de la ortografía oficial, académica, los impresores practican "de oficio", un ars punctandi, unas convenciones generalizadas, pero no totalmente estandarizadas. Hemos ilustrado este fenómeno, por ejemplo, con relación a la secuenciación gráfica y al cambiante empleo del espacio en blanco para la separación entre palabras, en los impresos del siglo XVI (Llamas-Pombo 2009). Ahora bien, entendemos que "irregularidad" no implica "arbitrariedad".

a) Este impreso no presenta puntuación de las enumeraciones:

Firmes fuertes 7 seguros (fol. 25vb)

b) Pero sí presenta un uso estereotipado de la puntuación delante de la conjunción $e$ en binomios que expresan:

- acciones o elementos complementarios o antitéticos,

- nociones sinónimas o cuasi-sinónimas.

El uso es variable y la aparición o no del signo de puntuación no responde a criterio alguno; es la variación gráfica propia del sistema de escritura prenormativo. 
b.a) Acciones o elementos complementarios o antitéticos puntuados:

Si discrecion: 7 saber (fol. 4vb)

Quanto creyeron: 7 honraron

(fol. 10ra) [cuan-to-cre-ye-ron-ybonra-ron $=8]$

Los ancianos

Molestando: 7 ofendiendo

(fol. 12va) [mo-les-tan-do-eo-fendien-do = 8]

Capitulo J de amor: 7 temor.

b.b) Nociones sinónimas o cuasi-sinónimas puntuadas:

Con estudio: 7 diligencia

(fol. 10va)

Distinguir: 7 conocer

(fol. 11vb)

Mas dañar: 7 destroyr

(fol. 16va)

b.c) Nociones sinónimas o cuasi-sinónimas sin puntuación

Ca sus lineas 7 senderos

(fol. 7vb)

De punir 7 castigar

(fol. 14rb)

Nin las leyes 7 derechos

(fol. 16rb)

La beldad 7 fermosura

(fol. 19rb)

En las ocurrencias que sí se presentan puntuadas, el comma subraya gráficamente el valor conectivo de la conjunción, pudiendo corresponder o no a una pausa o frontera prosódica, dependiendo del modo como se desee leer el verso. Solo en los raros casos de valor pragmático como conector a nivel de la enunciación, el comma impondría una pausa lógica. Por ejemplo:

Oye: 7 decontinente

(fol. 9ra)

Jamas libres

Nos interesan más, sin embargo, los casos de sinalefa. El modelo gráfico acorde con la norma puntuaria actual correspondería a aquel que no intercala signo alguno entre las dos sílabas unidas por una sinalefa. Se trata, no obstante, del caso menos frecuente:

Ama 7 honra la verdad (fol. 24vb)

[El octosílabo se lee con sinalefa: "a-mae-hon-ra-la-ver-dad", 7 sílabas + 1 acentuada]

$\mathrm{Al}$ contrario, en numerosos versos de ocho sílabas, el signo de puntuación empleado no puede representar ningún valor pausal interno, porque la última sí- 
laba de una palabra seguida de comma forma una sinalefa o sílaba única con la conjunción $e$. Se trata de la aplicación de una larga tradición de puntuación mediante un signo carente de valor oral de pausa, pero dotado de un valor visual de conexión o refuerzo gráfico del sentido copulativo de las conjunciones. Veamos algunos ejemplos:

Ha fecho: 7 faze por nos

[El octosílabo se lee, en 7 sílabas +1 por terminar en sílaba acentua$\mathrm{da}$, con sinalefa, que marcamos en cursiva: "ha-fe-cho:e-fa-ze-por-nos"] (fol. 11ra)

Del mundo: 7 la monarchia

[El octosílabo se lee con sinalefa, que marcamos en cursiva: "del-mundo:e-la-mo-nar-chi-a" 8] (fol. 12rb)

Mas la gula: 7 la pereza

[El octosílabo se lee con sinalefa, que marcamos en cursiva: "mas-la-gula:e-la-pe-re-za" = 8] (fol. 17rb)

Con estudio: 7 diligencia

[El octosílabo se lee con sinalefa, que marcamos en cursiva: "con-es-tudio:e-di-li-gen-cia" = 8] (fol. 10va)

E punido: 7 desterrado

[El octosílabo se lee con sinalefa, que marcamos en cursiva: "e-pu-ni-doedes-te-rra-do" = 8] (fol. 17vb)

Paradójicamente, hay casos en los que sería útil el signo de puntuación para indicar que hay que evitar la sinalefa $y$, sin embargo, se presentan sin puntuar:

Ama 7 seras amado (fol. 4ra)

[El octosílabo se lee sin sinalefa: "a-ma\#e-se-rás-a-ma-do" = 8 sílabas]

\section{Puntuación del esquema métrico y enunciativo (s. XVI)}

Un tercer modelo de escritura en colecciones de refranes es aquel que contiene signos de secuenciación sintáctica, cuya función primaria es subrayar visualmente el carácter bimembre o trimembre que caracteriza el axis rítmico de los refranes. Describiremos como testimonio de tal modelo los Refranes glosados editados en Burgos por Alonso de Melgar en 1524. 
a) Además del calderón que permite visualizar el comienzo de cada paremia glosada, el comma es el signo de puntuación predominante, con función de marca secuencial del bimembrismo formal del refrán:

IQue a mal capellan:mal sacristan.

IPalabras y plumas:el viento las lleva.

IQuien a buen arbol se arrima:buena sombra lo cobija.

bimembrismo que adopta frecuentemente la fórmula A $y$ B, cuando $y$ es el nexo entre dos partes del discurso:

IIAl buey por el cuerno:y al hombre por la palabra.

también cuando $y$ es conjunción con valor de conector de un argumento coorientado (= 'y además'):

IH Habla roldan:y habla por tu mal.

o se trata de un conector con valor adversativo (= 'pero', 'sin embargo'):

IISanan llagas:y no malas palabras.

ILadre me el perro:y no me muerda.

IINadar y nadar:y haogarse a la orilla.

o con valor consecutivo (= 'y por consiguiente'):

IAyamos paz:y moriremos viejos.

El mismo signo visualiza el trimembrismo de algunos refranes:

IPerdi mi honor:diziendo mal:y oyendo peor.

(fol. 3r)

IQuien te haze fiesta:quien no la suele hazer:o te quiere engañar o te ha menester Esquema $a_{4} b_{4} a_{4}$ (fol. $5 \mathrm{v}$ )

b) El "escriptor" que puntúa el repertorio distingue bien el ritmo bimembre de las paremias, porque en las unimembres no hay puntuación secuencial:

IMalas son las burlas verdaderas

INo hay puta sin alcahueta (fol. $5 \mathrm{v})$

IDel agua mansa te guarda (fol. 4r)

Este último refrán presenta un caso prototípico de la no coincidencia entre $b i$ membrismo semántico y bimembrismo formal (distinción de Anscombre 2004, 
77). No hay aquí bimembrismo semántico, sino una sola unidad: 'Guárdate del agua mansa', compuesta sobre una estructura rítmica trimembre, con rima asonante en $a_{3} a_{2} a_{3}$.

$\cup \underline{a} \underline{a} / \underline{a} \underline{a} / \cup \underline{a}$

c) Particularmente interesante es el tercer tipo de puntuación: existen proverbios trimembres, que contienen en realidad dos enunciados sentenciosos ligados, en los que el tercer miembro implica un empleo de la conjunción $y$ con valor de conector pragmático entre diferentes enunciados; $y$ funciona más al nivel de estructuración de la enunciación que como nexo entre unidades del enunciado.

ILa boca que dize no:dize si. Y a la larga

el perro a la liebre mata

IIAl que dios quiere bien:la casa le sabe. $\mathrm{Y}$ el aumen

tar: no se haze por mucho madrugar.

IDar a sant Pedro. Y no tanto que hombre se aya de yr tras el.

IIMas vale perder:que mas perder. $\mathrm{Y}$ del mal siem= pre se deve escoger lo menos.

El sistema de alternancia entre dos signos marca una conexión a dos niveles: el comma funciona en el nivel del enunciado; el punto, al ir seguido de mayúscula, conlleva un nivel de rango superior, que interviene a nivel de la enunciación. Ahora bien, obsérvese que la diferencia entre ambos signos es de tipo enunciativo y que no conlleva claramente ninguna gradación pausal.

Si revisamos la teoría sobre la puntuación de aquellos autores que definen un sistema mínimo basado en dos signos, comma <:> y punto <.>, observamos que la teoría renacentista no recoge el valor conectivo del punto que acabamos de ejemplificar. En 1502, por ejemplo, Nebrija distingue, en su gramática del latín, entre el comma, para unir lo que actualmente denominaríamos proposiciones o partes de la frase, y el colon, para marcar el final de la frase (Santiago 1996, 274-75; Sebastián Mediavilla 2002, 7). El valor ilativo del punto aparece en la doctrina de Nebrija, cuando define lo que Gasparino Barzizza denomina en Francia hacia 1440 el punctus copulativus (Llamas-Pombo 2007, 22) esto es, el colum que sirve para yuxtaponer sin conjunciones partes de la oración, como en el ejemplo aducido por Nebrija: Grammaticus . rhetor . geometres , pinctor aliptes. 
La presencia del punto delante de la conjunción y casa mal con la teoría de que un punto marca un fin de frase. Detectamos así un uso muy extendido del punto, desde los textos medievales (Llamas-Pombo 2007, 21-22), como signo de nexo o ligazón, que no aparece definido por los teóricos del ars punctandi. Ello implica que, también en el Renacimiento, hay divergencia entre los tratados ortográficos y las prácticas de los usuarios de la puntuación. De ahí la necesidad de detectar y registrar principios gráficos de los "escriptores", no preceptuados por la doctrina gramatical.

\section{Puntuación del esquema métrico y enunciativo (ss. ХVI-XVII)}

Con la finalidad de datar en los usos impresos la evolución del sistema de puntuación, compararemos dos ediciones de los Refranes o proverbios de Hernán Núñez de Toledo, las de Salamanca de 1555 y Lérida de 1621. Este filólogo y humanista, colegial en Bolonia y discípulo de Nebrija, realizó la recopilación impresa de refranes en español, catalán, valenciano, asturiano, gallego, italiano, francés y portugués más extensa de cuantas existen en su época. Los analiza como lexicógrafo, como etimologista, como dialectólogo y los regulariza métricamente (Madroñal).

Las ediciones de 1555 y 1621 presentan un sistema de puntuación en el que alternan el comma <:>, la coma moderna <,> y el punto <.>. La triada de figuras gráficas ha cambiado desde el sistema del 1500, pero algunos valores de la puntuación permanecen. Cambia la alternancia entre signos; hemos observado en el epígrafe anterior un sistema en que el signo de secuenciación predominante era el comma <:>, mientras que el signo secundario de secuenciación de unidades de rango superior era el punto <.>. Las ediciones en cuestión presentan una alternancia distinta: el signo de secuenciación predominante es la coma <,> sustituida, en menor proporción de casos y en unidades de rango superior, por el comma <:>. La puntuación responde así a cuatro funciones:

a) Marca de la estructura bimembre o trimembre de la paremia, en la edición de 1555:

Abaxan se los adarues, y alçan se los muladares

[Estructura bimembre]

A barbe du fol, apprent on a raire

[Estructura bimembre] 
Agua y sol para las huertas es lagarta, y para la uiñas pulgon

A bue $n$ comer, o mal comer, tres [Estructura trimembre] ueces beuer.

En la edición de 1621:

A Dios rogando, y del maço dando. (ed. 1621, fol. 3r) [Dos miembros unidos por $y$ con valor pragmático de nexo entre dos unidades de discurso]

A buscar la ando, la mala de la rueca, (ed. 1621, fol. 2v) y no la hallo.

[Tres miembros y empleo de $y$ con valor pragmático de nexo entre dos unidades de discurso]

b) Marca de la estructura cuatrimembre, por medio de alternancia de signos, con dos niveles de secuenciación. Nótese que ambos niveles conciernen a la jerarquía sintáctica, pero no conllevan claramente dos niveles de pausa de diferente duración (una pausa más breve y una pausa mayor);

Abril frio, hinche el silo: moja-

do, silo y campo.

Abril frio, hinche el silo:mojado, silo y campo. ～(ed. 1621, fol. 2r)

[Las ediciones contemporáneas emplean para esta alternancia la coma y el punto y coma. Por ejemplo: Abril frío, binche el silo; mojado, silo y campo, ed. Martínez de Carnero. En efecto, la estructura del refrán responde a cuatro unidades métricas unidas dos a dos: $a_{4} a_{4} b_{3} b_{4}$ ]

c) Marca de conexión delante de la conjunción y. La edición de 1555 presenta una puntuación de elementos coordinados en los que la coma no precede a la conjunción y (Ajo y vino puro, y luego veras quien es cada vno; Abril frio, pan y vino; Agua y sol para las huertas...). Sin embargo, la edición posterior, de 1621 , presenta aún la tradicional puntuación de la conjunción $y$, no conforme con nuestra norma contemporánea.

La marca estereotipada de la conjunción prevalece sobre la notación de pausas obligatorias. Por ejemplo, la pausa propia del encadenamiento en enu- 
meraciones, en un sistema de puntuación como notación de la pronunciación, impondría una coma entre médico y confesor, igual que, entre "manda" y "manda” en los dos refranes siguientes:

$\mathrm{Al}$ medico confesor, y letrado, no

le ayas engañado.

(ed. 1621, fol. 5r)

[Según la norma actual: "Al médico, confesor y letrado no le hayas engañado"]

Manda manda, Pedro, y anda.

[Según la norma actual: "Manda, manda,

Pedro, y anda"]

(ed. 1621, fol. 70r)

Abril, y Mayo, la llave de todo el año.

[Según la norma actual: "Abril y mayo,

la llave de todo el año"]

(ed. 1621, fol. 2v)

Abril frio pan, y vino. [Según la norma actual: "Abril frío, pan y vino"] De otra manera Abril frio, mucho pan, (ed. 1621, fol. 2r)

y poco vino.

Obsérvese, igualmente, que la puntuación no se aplica como "norma" absoluta: la variación característica de la puntuación del 1500 permanece: este último ejemplo presenta las dos variantes de un refrán que proporciona Hernán Núñez, con distinto uso de la coma.

d) En casos de sinalefa, la coma que precede a la conjunción y no puede representar una pausa, sino que se trata de una mera tradición gráfica.

Agua fría, y pan caliente [= 8 sílabas, con sinalefa en "frí-ay"] nunca hicieron buen vientre [= 8 sílabas] (ed. 1621, fol. 4r)

El modelo del refrán "Manda manda, Pedro, y anda", presenta el caso tipo de sinalefa entre dos vocales. Si leemos un esquema métrico $a_{2} a_{2} b_{2} a_{2}$, "manda/man-da/pe-droy/an-da", la sílaba droy anula un posible valor pausal de la coma. Este esquema métrico responde a la estructura:

$\begin{array}{ll}\leq \cup & \text { á a } \\ \leq \cup & \text { á a } \\ \leq \cup & \text { é oy } \\ \leq \cup & \text { á a }\end{array}$




\section{CONCLUSIONES PARA LA HISTORIA DE LA PUNTUACIÓN ESPAÑOLA}

a) Una propiedad habitualmente atribuida a los refranes es su oralidad; pero esta propiedad puede referirse a diferentes hechos que han de ser diferenciados. Los compiladores de refranes y autores de obras literarias con estrofas basadas en paremias atribuyen habitualmente al habla de un locutor indefinido la unidad fraseológica en cuestión (dicen las viejas; dice el gallego; ce dit li vilains, en textos medievales franceses, etc.). Existe, en otro orden lingüístico, una oralidad implícita en el ritmo que imprimen la configuración métrica y las equivalencias de elementos verbales, porque el metro no es sino el resultado del ritmo, únicamente realizable en el acto del habla. Ahora bien, ninguno de estos dos rasgos de oralidad impide que la escritura registre de modo autónomo el ritmo de los refranes.

b) Las ocurrencias de unidades métricas o asimiladas a ellas en las que aparecen los signos comma <:> o colon <.> como marcas de la conjunción e/y demuestran que pueden ser empleados en contextos en los que es imposible realizar pausa, inflexión o frontera entre dos vocales. Se trata, por lo tanto, de una marca estereotipada de la coordinación de elementos y la conexión de enunciados; igual que el punctus copulativus, definido desde el siglo XV como "signo con valor de unión", o la virgula de algunos textos romances, el colon y el comma pueden tener un valor de "ilazón", de "nexo", que nada tiene que ver con las pausas orales, sino que constituye un refuerzo visual de la propia función conectiva y copulativa de $e / y$. Signos para el ojo, más que para la voz.

c) En la historia de la puntuación occidental, existe una continuidad ininterrumpida entre las triadas antiguas y medievales de signos de puntuación (del tipo comma, colon, periodon, en Catach 297; Sebastián Mediavilla 2001, 37 38; Luque Moreno 505) y las teorías renacentistas de la puntuación (por ejemplo: virgule, comma, point, en Dolet 1540; comma, colum, punto clausulare, en Ycíar 1548). La conclusión (b) es prueba de que estas triadas que distinguen una puntuación débil, una puntuación media y una puntuación fuerte, no pueden ser sistemáticamente asimiladas a una escala prosódica de pausas a tres niveles, porque el comma y el colon pueden desempeñar funciones sintagmáticas que nada tienen que ver con la notación de pausas.

d) Por lo tanto, la puntuación de textos impresos en los siglos XVI y XVII presenta tanto funciones de correspondencia con los patrones fónicos, como usos autónomos. Estos últimos no son exclusivos de la norma de puntuación contemporánea y de nuestros hábitos lectores especializados en la descodificación únicamente visual de la lengua escrita. 
e) Algunas funciones sintagmáticas del comma y del colon, tales como su valor conectivo, no están definidas en las artes punctandi medievales y renacentistas. Entendemos así que, igual que en la Edad Media, en el siglo XVI existía cierto grado de divergencia entre los usos y la teoría de la puntuación. Las doctrinas gramaticales pueden ayudarnos a entender los usos de autores e impresores, pero no podemos pensar que los tratadistas recogen todos los usos y menos aún su alto grado de variación. Ahora bien, valorar el grado de corrección de la puntuación antigua respecto a la norma actual puede conducirnos a un análisis anacrónico. Como contribución a la historia de la estandarización gráfica del español, sí hemos de describir cómo articulaban la lengua escrita los impresores como profesionales de la escritura; con qué grado de homografía o de variación, con qué particular relación entre la letra y la voz.

\section{OBRAS CITADAS}

\section{Fuentes primarias}

Correas, Gonzalo. Vocabulario de refranes. 2016. En Fernando Martínez de Carnero.

Marqués de Santillana, Íñigo López de Mendoza. Los p[ro]u[er]bios vtilissimos del Illustre cauallero do[n] Iñigo lopez de me[n]doza marques de Santillana con la glosa del dicho marques [e] co[n] la glosa del doctor Pero diaz de Toledo [...]. Salamanca: s.i., ca. 1500 [USAL BG/34600(1)].

Marqués de Santillana, Íñigo López de Mendoza. Iñigo lopez de mendoça por mandado del rey don fuan ordeno estos refranes que dizen las viejas detras del fuego: y van ordenados por la orden del.a.b.c. Sevilla: Jacobo Cronberger Aleman, 1522 [USAL BG/17438 (13)].

Marqués de Santillana. Refranes que dicen las viejas tras el fuego. Ed. Annachiara Sanna. 2016. En Fernando Martínez del Carnero.

Martínez del Carnero, Fernando, ed. Diccionarios y repertorios de refranes. 2008. 22 de julio de 2016. <http://www.martinezdecarnero.com/glossword/index.php>.

Núñez de Toledo y Guzmán, Hernán. Refranes o proverbios en romance. Salamanca: Juan de Cánova, 1555. 22 de julio de 2016 [Universitat de València. BH Z-03/081]. 
Núñez de Toledo y Guzmán, Hernán. Refranes o proverbios en romance. Lérida: Luis Manescal Mercader de Libros, 1621.

Núñez, Hernán. Refranes o proverbios en romance: con sus glosas y numerados según el orden en que fueron escritos en la edición príncipe, con indicación del folio. Eds. Louis Combet, Julia Sevilla, Germán Conde y Josep Guia. 2 vols. Madrid: Guillermo Blázquez, 2001.

Refranes glosados: enlos quales qualquier que con diligencia los quisiere leer ballara prouerbios:y marauillosas sentencias y generalmente a todos muy prouechosos. Burgos: Alonso de Melgar, 1524.

Estudios

Anis, Jacques. "Pour une graphématique autonome". Langue française 53 (1983): Le signifiant graphique. Dir. Jacques Anis. 31-44.

Anis, Jacques. "Les linguistes français et la ponctuation". L'information grammaticale 102 (2004): 5-10.

Anscombre, Jean-Claude. "Parole proverbiale et structures métriques". Langages 139 (2000): 6-26.

Anscombre, Jean-Claude. "Apuntes sobre la métrica de los refranes”. Letras de Hoje. Porto Alegre 39.1 (2004): 65-88.

Anscombre, Jean-Claude. "Matrices rythmiques et parémies". La Parole exemplaire: Introduction à une étude linguistique des proverbes. Eds. Jean-Claude Anscombre, Bernard Darbord et Alexandra Oddo. Paris: Armand Colin, 2012. 147-58.

Boucheron-Pétillon, Sabine. Les détours de la langue: Étude sur la parenthèse et le tiret double. Bibliothèque de l'Information Grammaticale. Lovaina/Paris: Peeters, 2003.

Bruthiaux, Paul. "Knowing When to Stop: Investigating the Nature of Punctuation". Language and Communication 13.1 (1993): 27-43.

Carrera Díaz, Manuel. "La punteggiatura nelle lingue iberiche”. Storia della punteggiatura in Europa. Dir. Bice Mortara Garavelli. Roma: Laterza, 2008. 295-338.

Catach, Nina. L'orthographe française à l'époque de la Renaissance. Ginebra: Droz, 1968.

Contreras, Lidia. Ortografía y grafémica. Madrid: Visor, 1994.

Coseriu, Eugenio. Lecciones de Linguiística general. Madrid: Gredos, 1981.

Dahlet, Véronique. Ponctuation et énonciation. Guayana-Guadalupe: Ibis rouge éditions, 2003. 
D’Andrea, Giulia. "Qui dit proverbe... dit rythme?”. Scolia: Revue de Linguistique 31 (2017): Le Proverbe. Forme, sens, rythme. Ed. Sonia Gómez-Jordana Ferary. 101-17.

Darbord, Bernard. "La rhétorique du proverbe". La Parole exemplaire: Introduction à une étude linguistique des proverbes. Eds. Jean-Claude Anscombre, Bernard Darbord et Alexandra Oddo. Paris: Armand Colin, 2012. 170-82.

Echenique Elizondo, M. ${ }^{a}$ Teresa, M. ${ }^{a}$ José Martínez Alcalde y Juan Pedro Sánchez Méndez. "Perspectivas en el estudio diacrónico de la fraseología en su amplitud hispánica (peninsular, insular y americana)". Fraseología española: diacronía y codificación. Eds. M. ${ }^{a}$ Teresa Echenique Elizondo, M. ${ }^{a}$ José Martínez Alcalde, Juan Pedro Sánchez Méndez y Francisco P. Pla Colomer. Madrid: CSIC, 2016. 17-32.

Figueras, Carolina. Pragmática de la puntuación. Barcelona: Octaedro, 2001.

Figueras, Carolina. "Pragmática de la puntuación y nuevas tecnologías". Normas 4 (2014): 135-60.

García-Borrón, Juan-Pablo. Un viejo maestro de lengua: el refranero. Barcelona: Universitat de Barcelona, 2016.

Hagège, Claude. L'bomme de paroles: contribution linguistique aux sciences humaines. Paris: Fayard, 1986.

Jakobson, Roman. "Lingüística y poética". Estilo del lenguaje. 1960. Ed. Thomas A. Sebeok. Madrid: Cátedra, 1974. 123-73.

Llamas-Pombo, Elena. "Réflexions méthodologiques pour l'étude de la ponctuation médiévale". Systèmes graphiques de manuscrits médiévaux et incunables français: Ponctuation, segmentation, graphies. Ed. Alexei Lavrentiev. Chambéry: Université de Savoie, 2007. 11-48.

Llamas-Pombo, Elena. "Ponctuer, éditer, lire: État des études sur la ponctuation dans le livre médiéval”. Syntagma: Revista del Instituto de Historia del Libro y de la Lectura 2 (2008): 131-73.

Llamas-Pombo, Elena. "Variación gráfica y secuenciación de la palabra en manuscritos medievales hispánicos". Los códices literarios de la Edad Media: interpretación, bistoria, técnicas y catalogación. Dir. Pedro M. Cátedra. San Millán de la Cogolla: Cilengua/Instituto de Historia del libro y de la lectura, 2009. 225-57.

Llamas-Pombo, Elena. "Le proverbe comme unité graphique autonome dans les manuscrits médiévaux". La Phrase autonome: Théorie et manifestation. Eds. Jean-Claude Anscombre, Bernard Darbord, Alexandra Oddo et Cé- 
sar García de Lucas. Gramm-R: Études de linguistique française 31. Bruselas: Peter Lang, 2016. 231-48.

Llamas-Pombo, Elena. "Administración y cultura escrita: manuscritos anglonormandos y manuscritos castellanos, siglos XII-XIV". Los modelos anglo-normandos en la cultura letrada en Castilla (siglos XII-XIV). Eds. Amaia Arizaleta y Francisco Bautista. Toulouse: Presses Universitaires du Midi (2018, en preparación).

López Serena, Araceli. "Historia de la lengua e intuición”. Rilce: Revista de Filología Hispánica 30.3 (2014): 691-704.

Luque Moreno, Jesús. Puntos y comas: la grafía de la articulación del habla. Granada: Universidad de Granada, 2006.

Madroñal, Abraham. "Los Refranes o proverbios en romance (1555) de Hernán Núñez, Pinciano”. Revista de Literatura 64.127 (2002): 5-39.

Marcon, Mario. "Les rythmes lexico-syntaxiques des parémies: la place du verbe". Revue Repères DoRiF 6 (2015): Recherches sur la syntaxe verbale en français et en italien. Hommage à Claire Blanche-Benveniste. Ed. A. Bramati. 1-18.

Martin, Philippe. "Intonation, rythme et eurythmie de locutions et proverbes français". La Parole exemplaire: Introduction à une étude linguistique des proverbes. Eds. Jean-Claude Anscombre, Bernard Darbord et Alexandra Oddo. Paris: Armand Colin, 2012. 159-69.

Nunberg, Geoffrey. The Linguistics of Punctuation. CSLI Lecture Notes 18. s.l.: CSLI, 1990.

Polo, José. Ortografía y ciencia del lenguaje. Madrid: Paraninfo, 1974.

Quilis, Antonio. Métrica española. 3. ed. Madrid: Ediciones Alcalá, 1975.

Rosenblat, Ángel. Fetichismo de la letra. Cuadernos del Instituto de Filología Andrés Bello. Caracas: Universidad Central de Venezuela, 1963.

Sánchez Iglesias, Jorge. "Puntuación y conexión". Arquitextura: fundamentos discursivos del texto escrito en español. Dir. José M. Bustos Gisbert. Salamanca: Universidad de Salamanca, 2013. 137-55.

Santiago, Ramón. "La puntuación según Nebrija". Dicenda: Cuadernos de Filología Hispánica 14 (1996): 273-84.

Santiago Lacuesta, Ramón. "Apuntes para la historia de la puntuación en los siglos XVI y XVII". Estudios de Grafemática en el dominio bispano. Eds. José Manuel Blecua, Juan Gutiérrez y Lidia Sala. Salamanca: Ediciones Universidad de Salamanca/Instituto Caro y Cuervo, 1998. 243-80.

Sebastián Mediavilla, Fidel. "La puntuación en el Siglo de Oro (teoría y práctica)". Tesis doctoral. Universitat Autònoma de Barcelona, 2001. 
Sebastián Mediavilla, Fidel. La puntuación en los siglos XVI y XVII. Cuadernos de Filología 3. Bellaterra: Universitat Autònoma de Barcelona, 2002.

Sebastián Mediavilla, Fidel. "A propósito del Persiles, la ortografía (puntuación y acentuación) de los textos de Cervantes”. eHumanista 36 (2017): 353-85. Todorov, Tzvetan. Théorie de la littérature: textes des Formalistes russes. Paris: Seuil, 1965.

Trapero, Maximiano y Elena Llamas-Pombo. "De la voz a la letra: problemas lingüísticos en la transcripción de los relatos orales I: la puntuación”. Revista de Dialectología y Tradiciones Populares 52 (1997): 19-46.

Védénina, Ludmilla G. Pertinence linguistique de la présentation typographique. Paris: Peeters-Selaf, 1989.

Zumthor, Paul. Parler du Moyen Âge. Paris: Minuit, 1980. 
PuNTUACIÓN DE LOS PROVERBIOS EN IMPRESOS (SIGLOS XVI Y XVII)

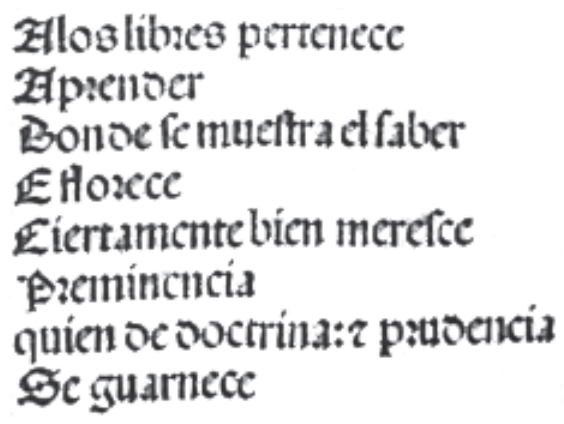

Fig. 1. Empleo del comma <:> ante la conjunción $e / y$.

Proverbios de gloriosa doctrina. Marqués de Santillana. Salamanca, ca 1500 [USAL BG/34600(1), detalle fol. 11r]

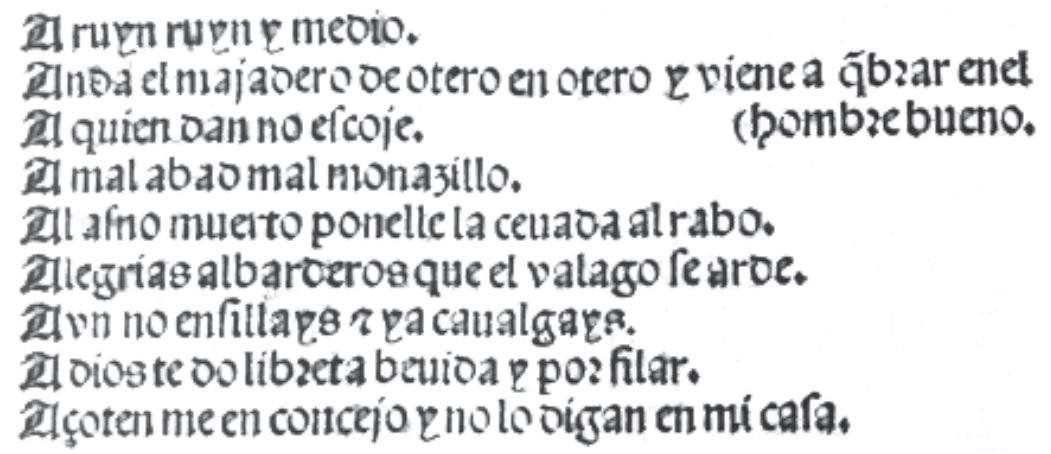

Fig. 2. Ausencia de puntuación entre los miembros del proverbio. Refranes que dizen las viejas. Marqués de Santillana. Sevilla: Jacobo Cronberger Alemán, 1522 [USAL BG/17438(13), detalle fol. 1v]

\section{T. In que fea enla mano oe sios todo poderofo oarte pzorper Aperidado míreria. Segun lo que oizen. C. Al que oios quiere bientla cafa le fabe. y el aume tar+nofe bazepozmucbo madrugar.}

Fig. 3. Puntuación de secuenciación del enunciado sentencioso a dos niveles, mediante alternancia del comma <:> y el punto <.>. Refranes glosados.

Burgos: Alonso de Melgar, 1524 [USAL BG/17438(14), detalle fol. 6v] 


\section{Abadcs, rociodepanes: Abril frio, hinche el filo: moja- do,filo y campo.}

Fig. 4. Puntuación de secuenciación del enunciado sentencioso a dos niveles, mediante alternancia de la coma <,> y el comma <:>. Refranes. Hernán Núñez.

Salamanca: Juan de Cánova, 1555 [BNE, U/1209, detalle fol. 7v]

\section{A scil frio pan,y vino. De our a miney a sioril fio, rsucho pan, A braga, rota compañon fano. $A$ bril frio, hinche el filo: mojado, it lo y campo. A gua fria, y pan caliente nunca hi zierun bucn vientre.}

Fig. 5. Puntuación de secuenciación del enunciado sentencioso a dos niveles, mediante alternancia de la coma <,> y el comma <:>. Empleo de la coma <,> ante la conjunción e/y. Refranes. Hernán Núñez. Lérida: Luis Manescal, 1621 [BNE, U/4577, detalle fols. 2r y 4r] 